\title{
RESEARCH ON IMPROVED AND ENHANCED OIL RECOVERY IN ILLINOIS THROUGH RESERVOIR CHARACTERIZATION
}

Grant \#DE-FG22-89BC14250

$\mathrm{DOE} / \mathrm{BC} / 1.4250-12$

DE92 040383

State of Illinois

Department of Energy and Natural Resources Illinois State Geological Survey

Grant Date: June 28, 1989

Anticipated Completion: June 27, 1993

Funding for FY92: $\$ 660,000$

Principal Investigator:

Donald F. OItz

Illinois State Geological Survey

Project Manager:

R. Michael Ray

Bartlesville Project Office

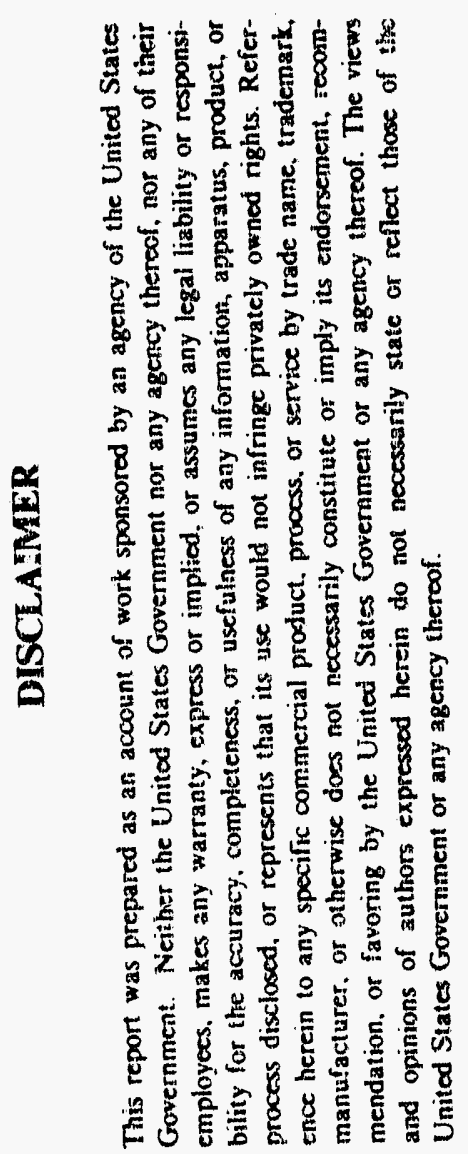

Reporting Period: March 28, 1992 through June 28, 1992

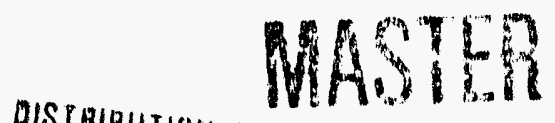




\section{OBJECTIVE}

This project will provide information that can maximize hydrocarbon production, minimize formation damage and stimulate new production in Illinois. Such information includes definition of hydrocarbon resources, characterization of hydrocarbon reservoirs, and the implementation of methods that will improve hydrocarbon extractive technology. Increased understanding of reservoir heterogeneities that affect oil recovery can aid in identifying producible resources. The transfer of technology to industry and the general public is a significant component of the program.

The project is designed to examine selected subsurface oil reservoirs in Illinois. Scientists use advanced scientific techniques to gain a better understanding of reservoir components and behavior and address ways of potentially increasing the amount of recoverable oil. Initial production rates for wells in the Illinois Basin commonly decline quite rapidly and as much as 60 percent of the oil in place can be unrecoverable using standard operating procedures.

Heterogeneities (geological differences in reservoir make-up) affect a reservoir's capability to release fluids. By-passed mobile and immobile oil remain in the reservoir. To learn how to get more of the oil out of reservoirs, the ISGS is studying the nature of reservoir rock heterogeneities and their control on the distribution and production of bypassed, mobile oil.

\section{SUMMARY OF TECHNICAL PROGRESS}

\section{Mapping, Cross Sections, Subsurface Depo-Systems (Task 2)}

\section{Bartelso Field}

The Bartelso Field study: "Reservoir Heterogeneity and Potential for Improved Oil Recovery within the Cypress Formation at Bartelso Field, Clinton County, Illinois is being printed.

\section{Boyd Field}

Boyd field has been rewritten after peer review.

\section{Dale Consolidated Field}

Sandstone bars in the Aux Vases Formation at southwest Dale Consolidated Field constitute structurally modified stratigraphic traps. Sandstone bars are "shingled", and separated by shale beds less than three feet thick. Petrographic analyses reveal a distinct upper zone of higher permeability within the reservoir interval. We are continuing to investigate the nature of hydraulically induced fractures and their adverse affects on oil production in the McCreery Waterflood Unit (McCreery/McCullum bar). Osburn Waterflood Unit (currently inactive) in the Cantrell bar was also hydraulically fractured 
and oil production may be adversely affected, as well. Similarities between the two units are being investigated.

\section{Energy Field}

The Energy Field manuscript has gone through peer review and is currently being revised before going to publication.

The simulation modeling of the Energy field is near completion. A two-dimensional model and a single-well radial model were used to study the effects of early water injection for pressure maintenance and wellbore formation damage on productivity of Energy field respectively. The effectiveness of the historical water injection programs was also studied using a 3-D full-field reservoir model. Finally, an optimal incremental oil recovery strategy based on the simulated results is suggested.

\section{Xenia East Field}

Oil reserves have been re-evaluated by reinterpreting Xenia East Field pay zone thickness using well logs. OOIP was calculated by volumetric methods using both a Monte Carlo method and planimeter measurement. Calculated results match the actual production data. Probability distribution graphs have been completed.

\section{Lawrence Field}

Lawrence Field is in the mapping and petrographic analysis phase. Engineering analysis and simulation has been initiated.

\section{Mattoon Field}

Intraformational analysis (Phase 2) of the Cypress Formation is in progress. Recent corrections to the regional well database has required necessary changes to the Mattoon Field basemap, subsequent existing cross sections, interformational structure maps (Phase 1), and intra-Cypress structure, isopach and facies maps (Phase 2). The database has been expanded from 440 to 663 well logs, for the purpose of mapping four complex intervals within the Cypress Formation. From lower to upper Cypress, these intervals have been arbitrarily named the Purple, Green, Brown and Yellow zones. Structure, $50 \%$ and $25 \%$ net isopach and lithofacies maps are either completed or nearly completed for each of the four Cypress intervals.

\section{Oakciale and Markham N. Fields}

Mapping is in progress. 


\section{Richview Field}

Richview Field is in the final stages and volumetric calculations, final map interpretations and initial manuscript preparations are in progress.

Richview Field has produced over 3.2 million barrels of Cypress oil from 86 wells on 800 acres to date. Although some production is attributed to an upper stray sandstone that immediately underlies the Barlow Limestone, a majority of the oil has been produced from the upper 20 feet or less of a sandstone, the top of which is 10 to 30 feet below the base of the stray sand horizon. This sandstone varies in thickness from 20 to 50 feet and displays a very clean, blocky SP log character. Increases in thickness occur as incremental, blocky sands, 10 to 20 feet thick, indicating a stacking of genetic depositional units. Log indications show thin, laterally traceable shales separate these sand units.

The northeast, southwest trending field appears to be largely stratigraphically controlled. The sandstones change facies to shale rapidly away from the field. Structurally the field lies in a saddle between lrvington Field to the north and Ashley Field to the south. Richview Field lies immediately west of and on the uplifted limb of the Du Quoin monocline.

\section{Stewardson Field}

Reservoir characterization of the Mississippian Aux Vases Formation at Stewardson Field in southeastern Shelby County, Illinois is in press.

\section{Storms Field}

Samples from the Cypress, and Aux Vases have been submitted for thin section and clay analysis. Preliminary cross sections, structure maps and isopach maps have been constructed.

\section{Tamaroa Field}

The Tamaroa Field study is at the editing and drafting stage. Reservoir compartmentalization and pressure maintenance control cumulative production and ullimate recovery efficiency. Maximum production is obtained by draining and pressure maintaining separate, correlative sandstones from a vertically stacked, multilateral marine bar setting. Both marginal and very successful production programs are apparent within the multiple oil reservoirs of Tamaroa and Tamaroa South fields. Recovery of 40 to 60 thousand barrels of oil per well from 10 acre spacing and less than 10 feet of reservoir thickness are typical where pressure is maintained within distinct, correlative sandstone bodies. Recovery efficiency for the more effectively managed reservoirs is $43 \%$. 


\section{Zeigler Field}

An integrated geological modeling and reservoir engineering simulation study on Zeigler field, Franklin county is near completion. A reservoir model capable of simulating the oil, water production and pressure history of the 30 productive wells over thirty years of production period has been constructed.

This model estimates that the original oil in place of the Plumfield lease to be 4.5 MMSTB and the overall after waterflood recovery to be $43 \%$. Simulation results showed that oil recovery of the eastern portion of Plumfield could have been better if pressure maintenance were started earlier. Unrecovered mobil oil (UMO) distributions have been identified for possible future implementation of improved oil recovery technology.

The first draft of the field study is in review.

\section{Outcrop Studies (Task 2)}

The regional Cypress outcrop work was completed in April and a manuscript is in preparation. Nearly 50 different outcrops were visited and described in detail.

The data collection for the Interstate 57 project was also completed in April, entailing a total of 60 measured sections. Two core samples were taken at each section, and each section was logged with a hand-held gamma ray spectrometer along with field minipermeameter readings every six inches vertically. Photo mosaics were taken of each of the four roadcuts and depositional facies were drawn on a mylar overlay. Paleocurrent measurements were also taken at selected sites on each of the four roadcuts and rose diagrams were constructed. These diagrams were also placed on the overlay. The main goal of this project is to develop outcrop analogs for reservoir facies, and this work continues.

\section{Oil and Gas Development Maps (Tasks 2,5)}

Development of a computer generated series of maps to replace the older ISGS series of hand-drawn oil and gas development maps continues.

\section{Maps completed to date}

$\begin{array}{ll}\text { Alto Pass } & \text { McLeansboro } \\ \text { Benton } & \text { Mt. Vernon } \\ \text { Carbondale } & \text { Murphysboro } \\ \text { Carlyle } & \text { Nashville } \\ \text { Cave-In-Rock } & \text { New Burnside } \\ \text { Centralia } & \text { Noble } \\ \text { Clay City } & \text { Pinckneyville }\end{array}$




$\begin{array}{ll}\text { Du Quoin } & \text { Roaches } \\ \text { Effingham } & \text { Rosiclare } \\ \text { Fairfield } & \text { Shelbyville } \\ \text { Goreville } & \text { Thompsonville } \\ \text { Mattoon } & \text { Xenia }\end{array}$

\section{Maps in progress}

Carmi

Kinmundy

Louisville

Patoka

\section{Engineering Work (Task 3)}

A report on experimental investigations of formation damage in the Aux Vases Formation is near completion and will show experimental results obtained when Aux Vases Formation rock samples are flooded with mud clean-out acid $(15 \% \mathrm{Hcl}$ with additives) and injection water of various salinities. Data presented in this work includes thin sections, SEM/EDX and XRD analyses of Aux Vases sandstones from various oil fields. Permeability changes resulting from injection of fluids are explained with regard to rock mineralogical changes and can be used to establish the least damaging fluids for reservoir treatment in Aux Vases formation.

\section{SEM/EDX (Task 4)}

Data has been catalogued and readied for entry into the project database. Samples from mud clean out acid static and dynamic experiments were analyzed to determine reaction of minerals in particular diagenetic clay minerals to commonly used well treatment fluids. Emphasis was placed on analysis of minerals most commonly found in pore systems of Aux Vases sandstone reservoirs.

\section{PETROGRAPHIC SYNTHESIS}

Synthesis of petrographic data generated during the project is on-going. XRD data has been combined with porosity and permeability data (where available) to facilitate graphing, comparisons, correlations and statistical analyses of datii. A draft paper entitled "The Role of Diagenesis on Reservoir-Fluid Interactions ir the Aux Vases and Cypress Sandstones" has been prepared for peer review. 


\section{Seismic Study, King Field, Jefferson County, Illinois}

Ten and one-half miles of very high resolution, high fold, conventional reflection seismic data was acquired from King Field in Jefferson County, Illinois. This data was obtained to demonstrate a seismic technique which would detect subtle reservoir heterogeneity. Due to the lack of empirical data, an interactive approach was taken throughout the entire operation. Field tests, data acquisition, and data processing were all regulated by staff members to fit with existing geological data. Preliminary interpretation of the records has been integrated with well logs and vertical seismic profile data.

\section{Regional mapping}

Three work cross sections through Jefferson County are being completed.

\section{Clay Minerals (Task 10)}

The program for analysis of clay and other minerals has been refined to allow calculation of the total mineral content of a sample at accuracies and precisions that are adequate for a large number of applications. The analyses include a characterization of the clay minerals, which are often important to geological framework studies, and to completion and production problems. The basic costs of the analyses are quite low, although more costly methods have been developed that determine the location of the clay minerals with respect to open pores, within carbonate framework grains and cement, and beneath quartz overgrowths. The following graph illustrates the precision with which mineral content can be determined. 
Analysis of Carbonate in Two Aux Vases Fields

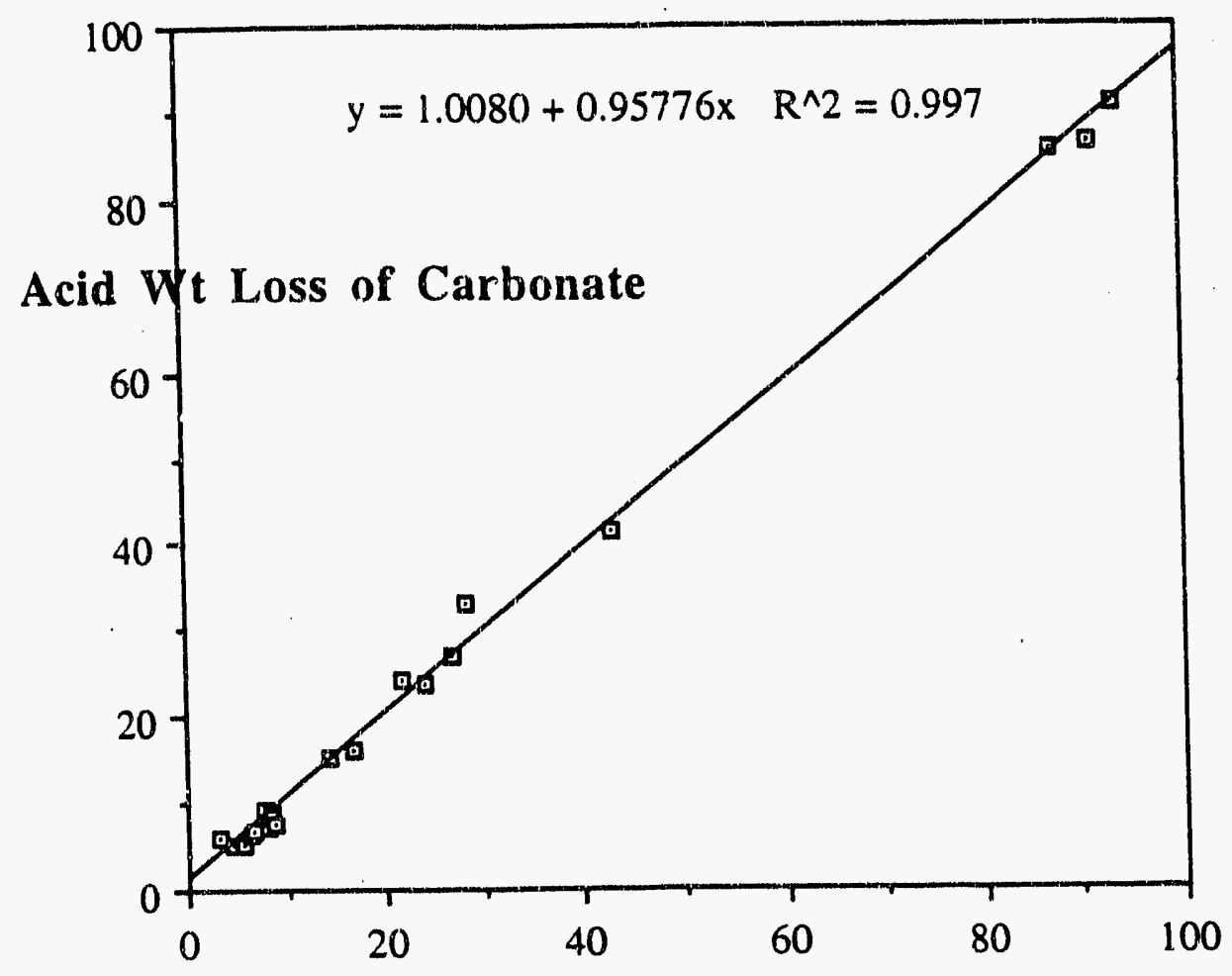

Carbonate Based on Peak Area Ratio

\section{Geochemistry of Formation Fluids for Reservoir Characterization and Enhanced Oil Recovery (Task 10)}

The Morgan Coal \#3 well in Energy Field was treated with mud cleaning acid (MCA) containing about $15 \% \mathrm{HC1}$. Production declined significantly after the treatment. The treatment of other wells with MCA containing $7.5 \%$ HC1 helped production. Reactions between the acid and the minerals and the water of the formation were modeled to predict likely cause(s) of the formation damage.

In response to treatinent with $15 \% \mathrm{HCl}-\mathrm{MCA}$ the geochemical model predicted a drastic increase in pore volume in the zone immediately adjacent to wellbore. A little further away from the well'sore, a slight decrease in porosity was predicted. On the other hand the model predicted relatively less but consistent increase in porosity in response to treatment with $7.5 \% \mathrm{HCl}-\mathrm{MCA}$ for all the zones modeled. Excess acidity and dissolved iron species were generated in the model when the well was treated with $15 \%$ HCl-MCA and increased the chance of asphaltene precipitation, which would reduce the permeability. The amount of acidity and dissolved iron species generated in response to 
treatment with $7.5 \% \mathrm{HCl}-\mathrm{MCA}$ was predicted to be relatively small. Thus, the treatment of the well with $7.5 \% \mathrm{HCl}-\mathrm{MCA}$ appears to be preferable over that with $15 \% \mathrm{HCl}-\mathrm{MCA}$. It is important to point out that this modeling is based on a number of assumptions that have not yet been verified. Furthermore, the model evaluates only chemical reactions. Physical changes, such as clay swelling, fines migration, and fracturing, can also affect the porosity and permeability.

\section{Technology Transfer (Task 12)}

Two team inembers presented a talk on "Optimizing Reservoir Management" to the local SPE chapter on February 20, 1992.

An application of 3-D modeling of the sandstone reservoir at King Field, Jefferson County, Illinois was presented at the 2nd Annual Reservoir Characterization Symposium on May 10-13, 1992, in Houston, Texas. 

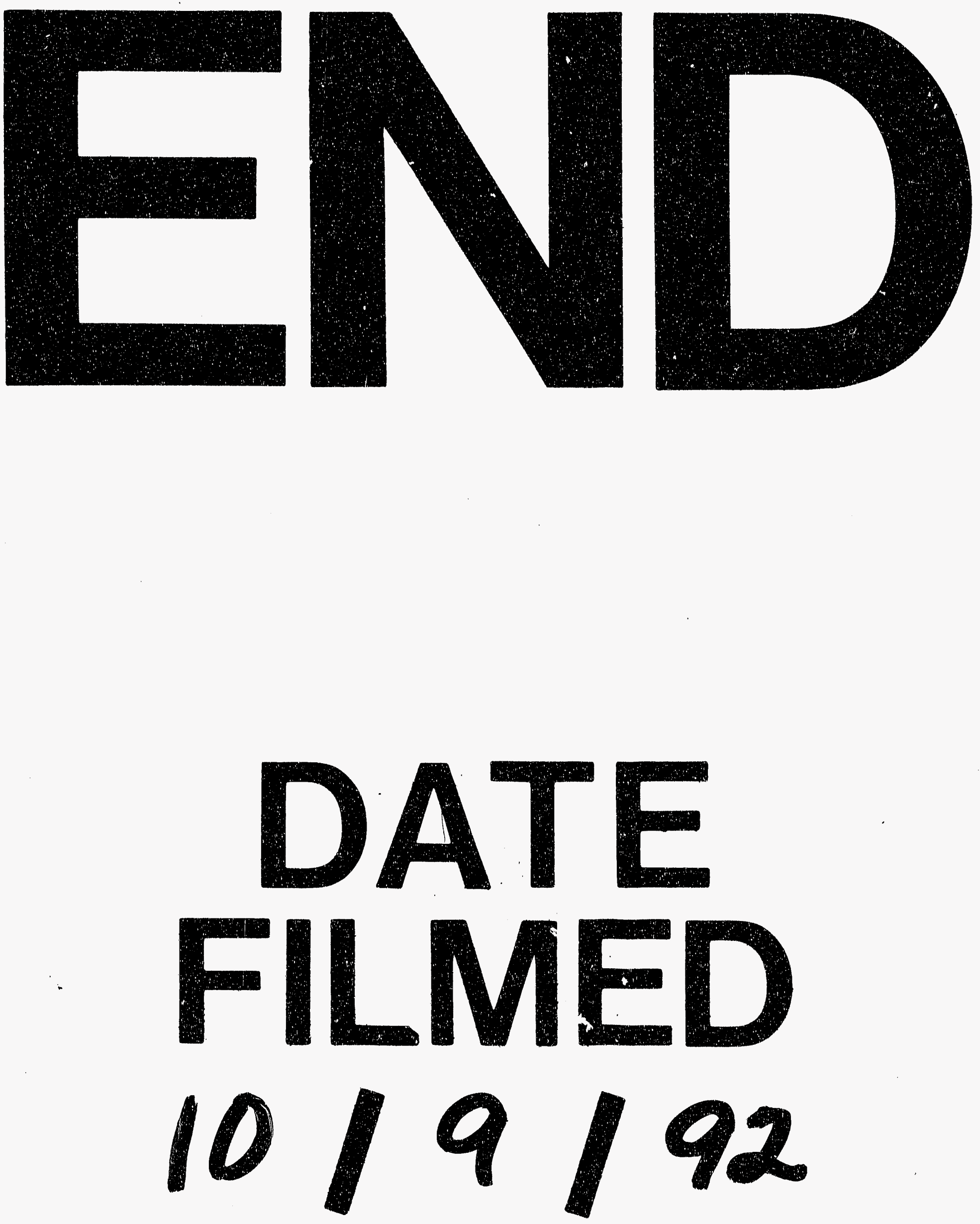


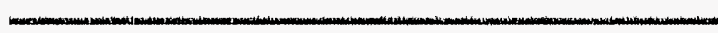

